Article

\title{
Effect of Laser Pulse Overlap and Scanning Line Overlap on Femtosecond Laser-Structured Ti6Al4V Surfaces
}

\author{
Georg Schnell ${ }^{1, *}$, Ulrike Duenow ${ }^{1}$ and Hermann Seitz ${ }^{1,2}$ (I) \\ 1 Microfluidics, Faculty of Mechanical Engineering and Marine Technology, University of Rostock, \\ Justus-von-Liebig-Weg 6, 18059 Rostock, Germany; ulrike.duenow@uni-rostock.de (U.D.); \\ hermann.seitz@uni-rostock.de (H.S.) \\ 2 Department Life, Light \& Matter, University of Rostock, Albert-Einstein-Str. 25, 18059 Rostock, Germany \\ * Correspondence: georg.schnell@uni-rostock.de; Tel.: +49-381-498-9093
}

Received: 18 December 2019; Accepted: 20 February 2020; Published: 21 February 2020

check for updates

\begin{abstract}
Surface structuring is a key factor for the tailoring of proper cell attachment and the improvement of the bone-implant interface anchorage. Femtosecond laser machining is especially suited to the structuring of implants due to the possibility of creating surfaces with a wide variety of nano- and microstructures. To achieve a desired surface topography, different laser structuring parameters can be adjusted. The scanning strategy, or rather the laser pulse overlap and scanning line overlap, affect the surface topography in an essential way, which is demonstrated in this study. Ti6Al4V samples were structured using a $300 \mathrm{fs}$ laser source with a wavelength of $1030 \mathrm{~nm}$. Laser pulse overlap and scanning line overlap were varied between $40 \%$ and $90 \%$ over a wide range of fluences ( $F$ from 0.49 to $12.28 \mathrm{~J} / \mathrm{cm}^{2}$ ), respectively. Four different main types of surface structures were obtained depending on the applied laser parameters: femtosecond laser-induced periodic surface structures (FLIPSS), micrometric ripples (MR), micro-craters, and pillared microstructures. It could also be demonstrated that the exceedance of the strong ablation threshold of Ti6Al4V strongly depends on the scanning strategy. The formation of microstructures can be achieved at lower levels of laser pulse overlap compared to the corresponding value of scanning line overlap due to higher heat accumulation in the irradiated area during laser machining.
\end{abstract}

Keywords: femtosecond laser; ultrashort laser pulse; ablation threshold; Ti6Al4V; laser pulse overlap; scanning line overlap

\section{Introduction}

The topography of implants affects the cellular response and, consequently, the implant performance [1-6]. Therefore, the surfaces of titanium, as a widely common material for many biomedical applications, such as dental and orthopedic implants, has been treated in various ways to adjust a proper surface design. Sandblasting [7-11], chemical etching [9-11], and coatings [10] have been used for roughness modification of titanium surfaces for a long time and have been well investigated. Laser treatment of titanium has been found to be particularly advantageous compared to conventional surface structuring methods because it leads to less contamination of the surfaces [12] and offers the possibility of creating stochastic as well as precise deterministic structures in the microand nanometer range $[5,13,14]$. In particular, the potential of femtosecond (fs) laser structuring of titanium for use in biomedical implants has been shown in several studies [15-18]. This technique is superior to nanosecond laser treatments due to opportunity of creating surface topographies with a greater variety of patterns [19]. Basically, ultra-short pulse laser machining, such as fs laser structuring, 
also offers many advantages over short pulse laser treatment [20,21], for instance, a widely reduced deposition of debris and trace of melting or molten material [19].

Several studies focused on the effect of different fs laser parameters on the formation of nanoand microstructures on titanium surfaces. For example, the influence of laser fluence as well as the number and duration of pulses on the formation of surface structures on titanium has been studied. It has been demonstrated that the spatial periodicity of ripples is affected by the laser pulse duration, which ranges from $200 \mathrm{fs}$ to $800 \mathrm{fs}$ [16]. Furthermore, an increasing number of pulses per spot leads to a decreasing spatial periodicity of ripples [16], whereas the spatial periodicity of microstructures rises with a growing number of laser pulses [22]. An increase of the spatial periodicity of micrometric ripples (MR) has been observed with a rising number of laser pulses on Ti6Al4V surfaces [23]. Moreover, the formation of sharp conical microstructures on titanium surfaces due to fs laser irradiation in vacuum and in a helium atmosphere has been shown [24]. Other studies investigated the formation of highly regular laser-induced periodic surface structures [25] and the manipulation of the nanotopology by a spatially asymmetric fluence on titanium surfaces leading to the result that a shaped laser beam irradiation can result in smooth microstructures in contrast to a laser treatment with a Gaussian beam profile, which typically results in a pronounced double-scale roughness [26].

The process parameters laser pulse overlap and scanning line overlap, which also strongly affect the formation of structures on Ti6Al4V, have not been examined thoroughly in previous studies. This study systematically investigates the effects of both laser parameters on the surface texture of Ti6Al4V at different fluences. The laser pulse overlap is varied whereas the scanning line overlap is maintained constant and vice versa. Essentially, the resulting different dynamics of the fs laser structuring process are analyzed. The results can ultimately be used to optimize the scanning strategies for fs laser surface machining.

\section{Materials and Methods}

\subsection{Material}

The experimental investigations were carried out with Ti6Al4V samples that were cut by waterjet technology to a plate size of $8 \mathrm{~cm} \times 6 \mathrm{~cm} \times 0.4 \mathrm{~cm}$. The plates were purchased from S + D Spezialstahl Handelsgesellschaft $\mathrm{mbH}$, Stelle, Germany and the specifications of the material complies with the requirements of AMS4911 and WL 3.7164 Part 1. In order to ensure uniform surfaces with low roughness, the samples were polished with silicon carbide abrasive sandpaper under pure water in three steps. Initially, sandpaper with a grain size of P320 was applied for $8 \mathrm{~min}$ followed by sandpaper with a grain size of $\mathrm{P} 600$ for $4 \mathrm{~min}$ and then a grain size of P1200 for a further 4 min resulting in an average area surface roughness $S a$ of approximately $0.065 \pm 0.003 \mu \mathrm{m}$. The abrasive treatment was followed by cleaning in a Sonorex Super RK 100/K ultrasonic bath (Bandelin electronic GmbH and Co. KG, Berlin, Germany) with ultrapure water for $15 \mathrm{~min}$. Drying was applied with dust-free wipes and compressed air.

\subsection{Laser Treatment}

A 300 fs UFFL_60_200_1030_SHG fiber laser (Active Fiber Systems GmbH, Jena, Germany) featuring an amorphous glass $\mathrm{Yb}$-doped core was used for laser structuring. The laser system is integrated into a Microgantry GU4 five-axis micromachining center (Kugler GmbH, Salem, Germany). The pulse repetition rate of the laser system can be varied from $50.3 \mathrm{kHz}$ to $18.6 \mathrm{MHz}$, with an average power of up to $60 \mathrm{~W}$. The laser emits linear polarized light with a wavelength of $1030 \mathrm{~nm}$. An f-theta lens with a focal length of $163 \mathrm{~mm}$ leads to a circular focus diameter of $d_{f}=36$ microns at $1 / \mathrm{e}^{2}$ intensity (Gaussian laser beam profile). This spot diameter is used for all laser parameter calculations. A schematic illustration of the scanning arrangement and related scanning parameters are given in Figure 1. 


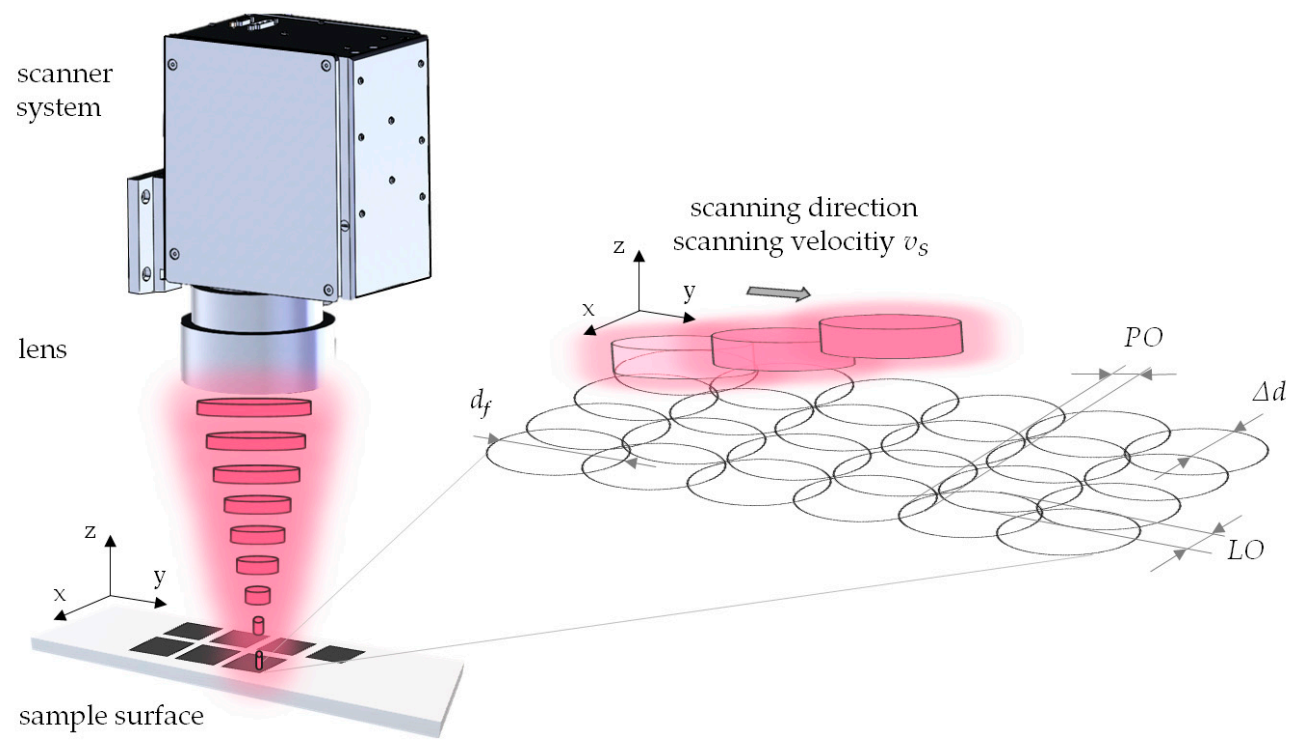

Figure 1. Schematic illustration of the laser surface structuring using a line-wise scanning strategy leading to a defined laser pulse overlap $(P O)$ and scanning line overlap $(L O)$. Deflecting in the $x$ and $\mathrm{y}$ directions of the Gaussian laser beam is evoked by the movement of galvanic mirrors within the scanning system.

The laser pulse overlap PO is calculated from Equation (1):

$$
P O=\left(1-\frac{v_{S}}{d_{f} \times f_{R E P}}\right) \times 100 \%
$$

where $v_{S}$ is the scanning velocity, $d_{f}$ the circular focus diameter and $f_{R E P}$ the repetition rate. The $L O$ is calculated according to Equation (2):

$$
L O=\left(1-\frac{\Delta d}{d_{f}}\right) \times 100 \%
$$

where $\Delta d$ is the space in scanning line arrangement and $d_{f}$ denotes the focus diameter. The $P O$ is varied in a range from $40 \%$ to $90 \%$ at a fixed $L O$ of $50 \%$ and vice versa. It is reported that the forming of periodic ripples on titanium surfaces starts at a fluence $F$ of about $0.5 \mathrm{~J} / \mathrm{cm}^{2}$ [27]. Accordingly, this value is used as the starting point for the applied fluence. Fluence is increased systematically, aiming at extensive formation of microstructures. Consequently, for every combination of $P O$ and $L O$, the pulse energy is varied from 5 to $125 \mu \mathrm{J}$ leading to a corresponding fluence range from 0.49 to $12.28 \mathrm{~J} / \mathrm{cm}^{2}$ (see Table 1). In the following, special attention is given to the fluence as the crucial laser parameter in material processing.

Table 1. Laser parameter setting. Laser pulse and scanning line overlap were varied for each pulse

\begin{tabular}{|c|c|c|c|c|c|c|c|c|c|}
\hline \multicolumn{10}{|c|}{ Laser Parameter Variations } \\
\hline Pulse energy $(\mu \mathrm{J})$ & 5 & 10 & 15 & 20 & 25 & 50 & 75 & 100 & 125 \\
\hline Fluence $\left(\mathrm{J} / \mathrm{cm}^{2}\right)$ & 0.49 & 0.98 & 1.47 & 1.96 & 2.46 & 4.91 & 7.37 & 9.82 & 12.28 \\
\hline $\begin{array}{l}\text { Laser pulse overlap }(P O)(\%) \\
\text { at fix } L O \text { of } 50 \%\end{array}$ & 40 & 50 & 60 & & 70 & & 80 & 90 & \\
\hline $\begin{array}{l}\text { Scanning line overlap }(L O) \\
(\%) \text { at fix } P O \text { of } 50 \%\end{array}$ & 40 & 50 & 60 & & 70 & & 80 & 90 & \\
\hline
\end{tabular}
energy/fluence value. 
The repetition rate of the laser was maintained constant at $f_{R E P}=226.8 \mathrm{kHz}$ to ensure a constant time interval between consecutive laser pulses. The different $P O s$ are achieved by the adjustment of the scanning velocities $\left(v_{S}\right.$ from 0.82 to $\left.4.9 \mathrm{~m} / \mathrm{s}\right)$ in accordance with Equation (1) and different LOs are realized by setting corresponding spacings ( $\Delta d$ from 4 to $32 \mu \mathrm{m}$ ) between the scanning lines in accordance with Equation (2). The number of overscans was maintained at a constant of 50. The structuring area is $0.7 \mathrm{~cm} \times 0.7 \mathrm{~cm}$.

\subsection{Surface Characterisation}

A LEXT OLS 4000 confocal laser scanning microscope (CLSM) (Olympus, Hamburg, Germany) was utilized to determine the elevation profile (depth and width of the resulting pillars and profiles, respectively) and the average area surface roughness $(\mathrm{Sa})$. A constant optical magnification $(50 \times)$ was used leading to a scan area of $256 \mu \mathrm{m} \times 256 \mu \mathrm{m}$. The resulting scans have a resolution of $1024 \times 1024$ pixels. For data calculation and visualization, OLS4000 software (Version 2.2.3, Olympus, Hamburg, Germany) was applied. For detailed images, a StereoScan360 scanning electron microscope (SEM) (Cambridge Instruments, Cambridge, UK) was used. The spatial periodicities of the femtosecond laser-induced periodic surface structures (FLIPSS) $\lambda_{1}$ and of the micrometric ripples (MR) $\lambda_{2}$ were determined by measuring the distances between periodic structures in the SEM images using ImageJ software (Version 1.52, available as freeware online from https://imagej.nih.gov/ij/), respectively. Each measurement was repeated five times.

\section{Results and Discussion}

\subsection{Surface Characterization}

All structuring experiments have been performed successfully leading to surfaces with different structural characteristics depending on the applied laser parameters and scanning strategy. When considering the results, four different types of structures can be basically distinguished. Figure 2 exemplarily shows the resulting structures for the structuring parameters $P O$ of $50 \%$ and $L O$ of $80 \%$ for different fluences. Structures can be found on the nanometer-scale, so-called femtosecond laser-induced periodic surface structures (FLIPSS) featuring a spatial periodicity $\lambda_{1}$ (see Figure 2a), as well as on the micrometer-scale, where micrometric ripples (MR) with a spatial periodicity $\lambda_{2}$ (see Figure 2b) can be distinguished from micro-craters (see Figure 2c,d) and pillared microstructures (see Figure 2e). Microstructures are typically superimposed by nanostructures.

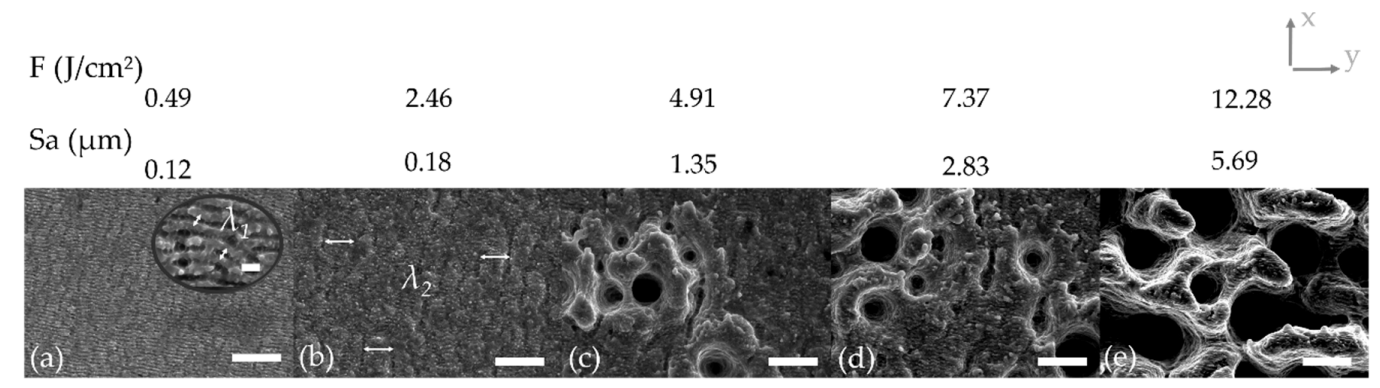

Figure 2. Formation of nano- and microstructures at a $P O$ of $50 \%$ and $L O$ of $80 \%$ with increasing laser fluence $F$. The y-axis indicates the scanning direction for the $P O$. The x-axis indicates the line feed direction for the LO. (a) Femtosecond laser-induced periodic surface structures, $\lambda_{1}=0.859 \pm 0.056 \mu \mathrm{m}$, scale bar $10 \mu \mathrm{m}$ and in detail $1 \mu \mathrm{m}$. (b) Micrometric ripples, $\lambda_{2}=5.038 \pm 0.829 \mu \mathrm{m}$, scale bar $10 \mu \mathrm{m}$. (c,d) Formation of micro-craters, scale bar $10 \mu \mathrm{m}$. (e) Pillared microstructures, scale bar $10 \mu \mathrm{m}$.

The ablation threshold, which represents the minimum energy density to remove material by laser treatment, plays a key role when considering the structuring results. The ablation threshold principally depends on the applied laser pulse duration [28], the laser wavelength [29], the number of pulses applied on the irradiated spot [30,31] and on the material itself [32]. Fluences slightly 
higher than the ablation threshold lead to the formation of FLIPSS. Interferences between the linearly polarized laser light and the excited surface plasmon polaritons lead to a uniform formation and orientation of these structures. The periodic FLIPSS arranged perpendicularly to the laser electric field polarization vector and the periodicity match the wavelength or is slightly smaller than the applied wavelength $[22,31,33,34]$. The determined spatial periodicity of the FLIPSS in Figure $2 \mathrm{a}$ in the study is $\lambda_{1}=0.859 \pm 0.056 \mu \mathrm{m}$ and, therefore, slightly lower than the applied laser wavelength of $1030 \mathrm{~nm}$. Furthermore, micro-ripples can be observed that are oriented parallel to the polarization of the laser beam. The formation of MR is related to hydrodynamic effects due to heat exposure in the liquid area by melting processes [23]. This double-scale formation of structures is caused by nonuniformity of the intensity distribution of the Gaussian laser beam and uniform motion of the spot, which is evoked by deflecting the laser light by the scanner system in this study [35]. The spatial periodicity of the MR in Figure $2 \mathrm{~b}$ was determined as $\lambda_{2}=5.038 \pm 0.829 \mu \mathrm{m}$. Low laser fluences in this so-called gentle ablation lead to an increase in temperature on the surface and, consequently, to melting and low evaporation, or rather sublimation of metals in tens of nanometers [36]. Therefore, the amount of ablated material depends on the optical penetration depth [31,37,38]. Melt splashing in this regime is negligible and phase explosion did not occur [32]. Once the fluence exceeds the strong ablation threshold, the ablation rate depends on the electron heat diffusion length [31,37] and is determined by the effective heat penetration depth [38]. The heat penetration depth characterizes the distance of effective heat energy transport via electrons [31]. The change of the ablation regime is explained by non-linear heating (superheating) of electrons in the conduction band [36,38] and the ablation in the regime is caused by phase explosion [31,36,39]. Particles mixed with the overheated liquid phase are emitted [30] and the resulting surface is substantially coarser leading to an increased roughness, as shown in Figure 2c-e. Phase explosion, also referred to as explosive boiling, results in an immense ejection of vapor and molten material that leads to a rapid and very large increase of the ablation rate [32,39] which can be observed in Figure $2 \mathrm{e}$ at a fluence of $12,28 \mathrm{~J} / \mathrm{cm}^{2}$. A more precise gradation of the ablation regimes is given in [32] where melt displacement and melt splashing are considered as new regimes between gentle and strong ablation. Melt displacement and melt splashing are explained by internal inhomogeneous vaporization of matter with different elements or external effects of vapor recoil or generated plasma pressure [32]. Melt displacement can be observed in Figure $2 c, d$ for the used titanium alloy and starts at a fluence of $4.91 \mathrm{~J} / \mathrm{cm}^{2}$ at a $P O$ of $50 \%$ and $L O$ of $80 \%$. Furthermore, the Gaussian-shaped laser beam features fluences in the strong ablation regime in the center of the spot whereas the intensity of the laser beam in the surrounding area is much lower. This leads to a partial coverage of the microstructures with nanostructures.

\subsection{Effects of Laser Pulse Overlap and Scanning Line Overlap on Texturing of Ti6Al4V}

The results of the parameter study with variable $P O$ at a fix $L O$ of $50 \%$ are shown in Figure 3 and with variable $L O$ at a fix $P O$ of $50 \%$ in Figure 4 , respectively. The results are depicted as a matrix of SEM images where the rows correspond to certain levels of fluence. The presented results at a certain position in matrices in both figures have been laser-treated with the same total energy since the levels of $P O$ and $L O$, respectively, are identical. Furthermore, the y-axis indicates the scanning direction for the laser beam (and, consequently, the direction for the $P O$ ) whereas the $x$-axis indicates the line feed direction for the $L O$ (Figures 3 and 4). Figures 5 and 6 show height elevation profiles for the structures created at two selected levels of fluence $\left(F=4.91 \mathrm{~J} / \mathrm{cm}^{2}\right.$ and $\left.F=0.49 \mathrm{~J} / \mathrm{cm}^{2}\right)$ for three levels of $P O s$ $(40 \%, 70 \%$, and $90 \%)$ and for three levels of LOs (40\%, 70\%, and 90\%), respectively. The associated SEM images of the structures can be found at the corresponding positions in the matrices in Figures 3 and 4 , respectively.

Through comparison of Figures 3 and 4 it can be concluded that the different scanning strategies have a major impact on the formed structures. Firstly, a low level of $L O$ leads to a clear formation of trenches in scanning direction. This effect can clearly be seen in Figure 3 at low fluences. Figure $5 b$ also shows that the depth of the trenches increases with increasing fluence. A low level of $P O$ results in the 
formation of dimple-like cavities, especially at low fluences as depicted in Figure 3. On the one hand, trenches can be avoided if the fluence exceeds the strong ablation threshold and microstructures are formed, as shown in Figure 5a. On the other hand, trenches can also be avoided by a sufficient level of $L O$, as can be seen in Figures 4 and 6. In particular, a sufficient level of $L O$ leads to a homogenous formation of nanostructures, as depicted in Figure $6 \mathrm{~b}$. The roughness data in Figure $7 \mathrm{~b}$ reflects the decrease in waviness by a lower $S a$ with increased levels of $L O$. Apart from fluences higher than the ablation threshold, all effects can be attributed to inhomogeneous energy distributions within the Gaussian laser beam profile and, therefore, nonuniform ablation. At a certain level of superimposition of laser pulses, a widely homogenous surface can be achieved.

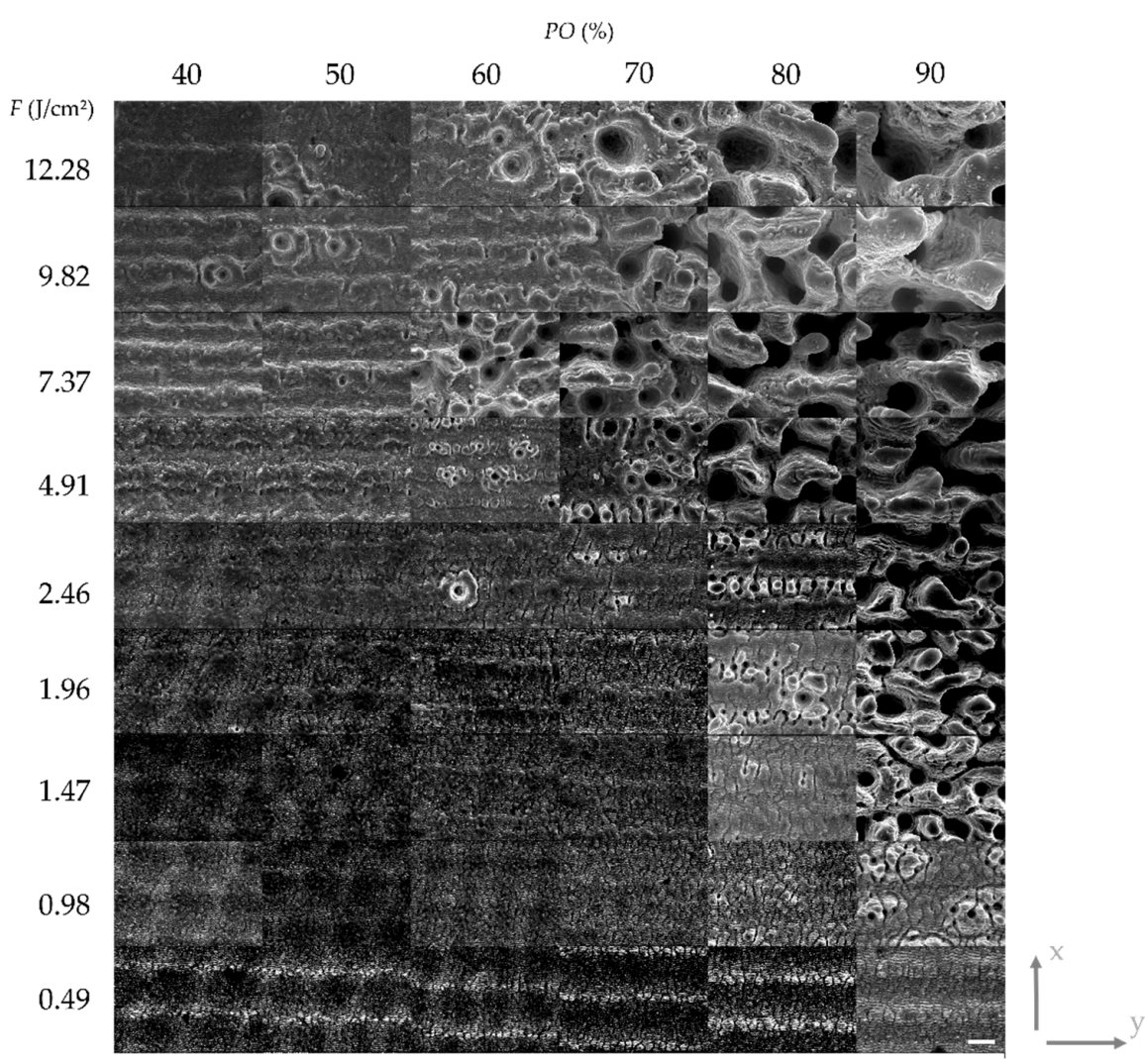

Figure 3. Structured Ti6Al4V surfaces with varied fluence $F$ and laser pulse overlap $P O$ in a matrix of SEM images. The y-axis indicates the scanning direction for the $P O$. The $\mathrm{x}$-axis indicates the line feed direction for the $L O$. Formation of microstructures can be observed at a fluence of approx. $0.98 \mathrm{~J} / \mathrm{cm}^{2}$ and higher. In particular at low fluences, a clear formation of trenches can be observed due to the $L O$ of $50 \%$ and inhomogeneous energy distributions within the Gaussian laser beam profile. By comparison of the structures irradiated with a constant $P O$ of, e.g., $90 \%$, it can be observed that the ablated craters become larger in terms of diameter and depth with increasing fluence (compare roughness data in Figure 7 and elevation profile in Figure 5). Scale bar: $10 \mu \mathrm{m}$.

It can be deduced from Figures 3 and $7 \mathrm{a}$, that high levels of $P O$ lead to a formation of microstructures already at low fluences. In contrast, Figures 5 and $7 \mathrm{~b}$ demonstrate that, at the corresponding levels of $L O$, microstructures only formed at higher fluences (e.g., compare $P O$ of $90 \%$ at $1.47 \mathrm{~J} / \mathrm{cm}^{2}$ in Figure 3 and $L O$ of $90 \%$ at $1.47 \mathrm{~J} / \mathrm{cm}^{2}$ in Figure 4). Even if the applied fluence is the same, it seems that the time sequence of the series of pulses plays a major role, especially in achieving the strong ablation threshold. This phenomenon is also confirmed by the comparison of roughness values resulting from different POs and LOs, as seen in Figure 7. Basically, the average area surface roughness $S a$ increases more at certain high levels of $P O$ than at corresponding levels of $L O$. Similar values for the $S a$ only achieved at higher fluences for the $L O$ if comparing corresponding levels of $P O$ and $L O$ (e.g., $S a=3.42$ 
$\mu \mathrm{m}$ for $P O=90 \%$ at $F=1.47 \mathrm{~J} / \mathrm{cm}^{2}$ vs. $S a=3.684 \mu \mathrm{m}$ for $L O=90 \%$ at $F=2.46 \mathrm{~J} / \mathrm{cm}^{2}$ ). To gain a better understanding of the responsible reasons for differences in $P O$ and $L O$ texturing, it is necessary to consider the dynamic of the ablation process in detail at various time-scales.

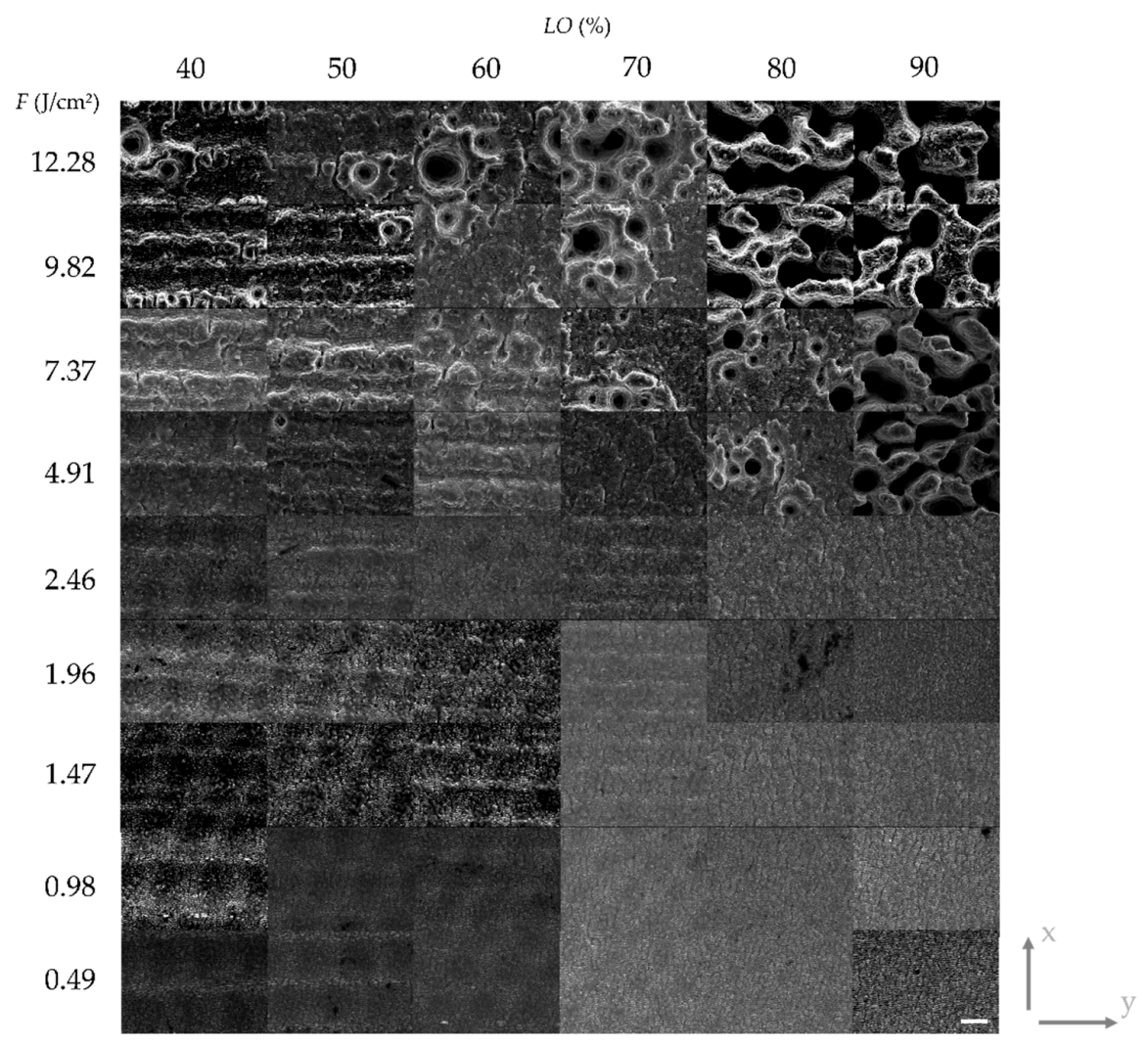

Figure 4. Structured Ti6Al4V surfaces with varied fluence $F$ and scanning line overlap $L O$ in a matrix of SEM images. The y-axis indicates the scanning direction for the $P O$. The $\mathrm{x}$-axis indicates the line feed direction for the $L O$. Formation of microstructures can be observed at a $F$ of approx. $4.91 \mathrm{~J} / \mathrm{cm}^{2}$ and higher. With an increasing $L O$, a more homogeneous surface with smoother trench formation is apparent (confirmed by elevation height profiles in Figure 6). Scale bar: $10 \mu \mathrm{m}$.

(a)

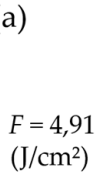

(b)

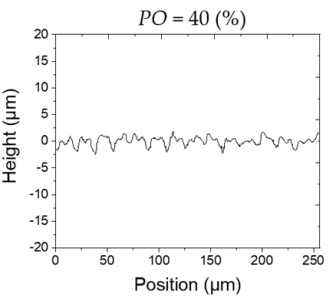

$F=0,49$

$\left(\mathrm{J} / \mathrm{cm}^{2}\right)$

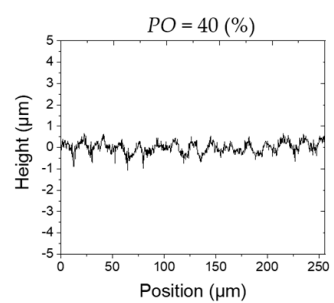

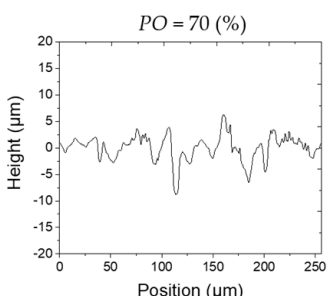
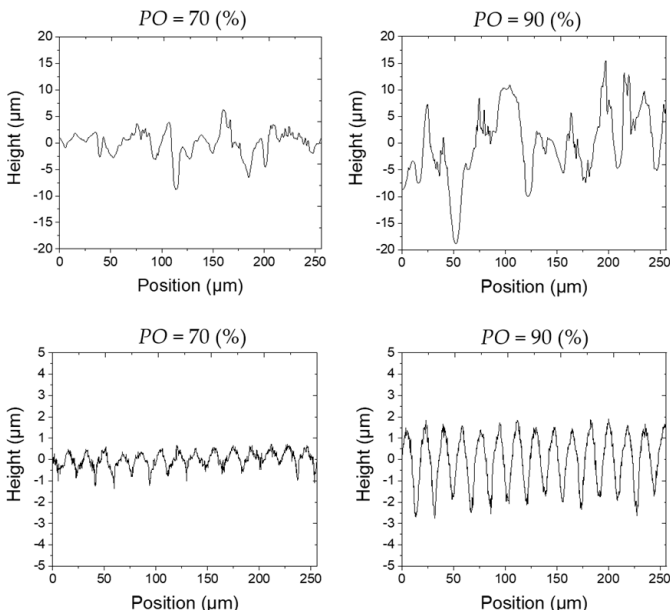

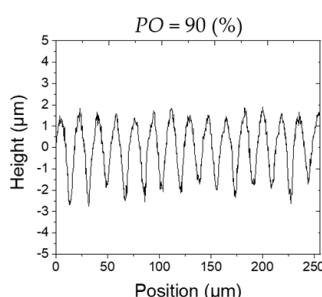

Figure 5. Exemplary height elevation profiles in x-direction for different $P O(40 \%, 70 \%$, and $90 \%)$ and different fluences $\left(F=4.91 \mathrm{~J} / \mathrm{cm}^{2}\right.$ and $\left.F=0.49 \mathrm{~J} / \mathrm{cm}^{2}\right)$, respectively. (a) A clear formation of stochastic microstructures can be observed at a high level of $P O$ at $F=4.91 \mathrm{~J} / \mathrm{cm}^{2}$. Width and height of the structures rise with increasing $P O$. (b) At $F=0.49 \mathrm{~J} / \mathrm{cm}^{2}$, the height of deterministic structures grows and periodicity remains constant with increasing $P O$. Structures are covered with nanoscale roughness. 

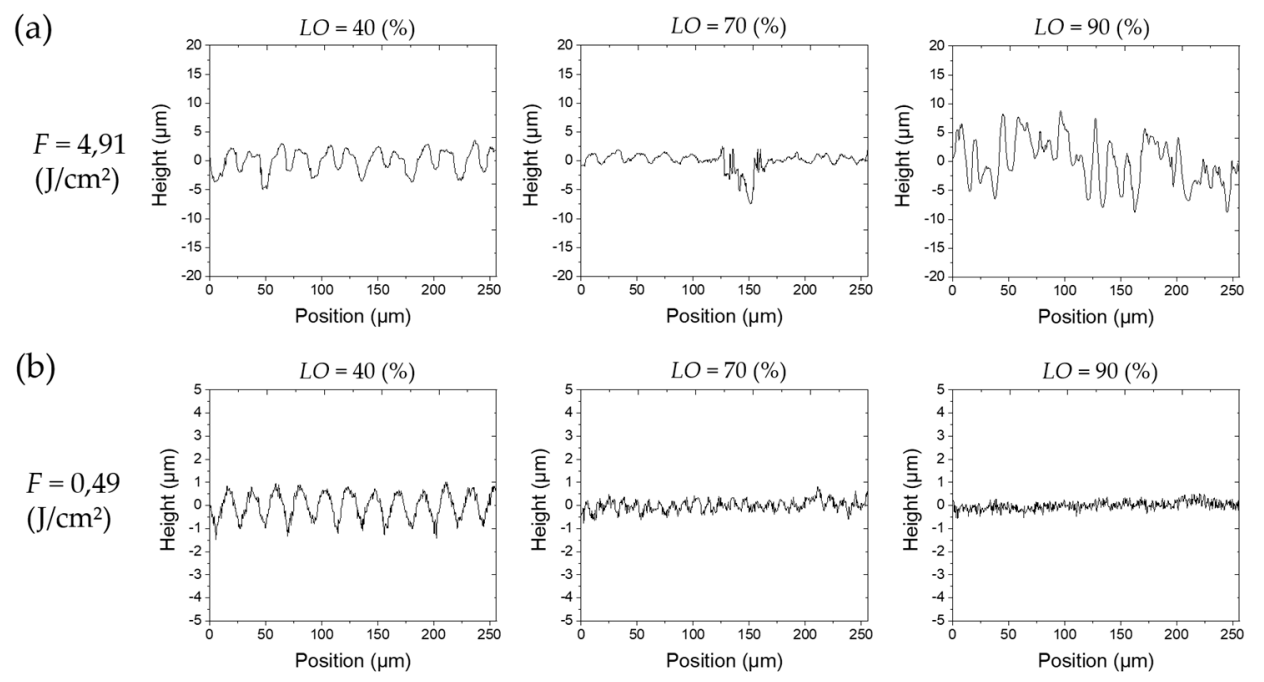

Figure 6. Exemplary height elevation profiles in x-direction at different $L O(40 \%, 70 \%$ and $90 \%)$ and different fluences $\left(F=4.91 \mathrm{~J} / \mathrm{cm}^{2}\right.$ and $\left.F=0.49 \mathrm{~J} / \mathrm{cm}^{2}\right)$. (a) Low levels of $L O$ lead to considerable formation of trenches $(L O=40 \%)$. Firstly, structures become smaller with increasing $L O$ ( $L O$ from $40 \%$ to $70 \%$ ). After reaching the high ablation regime, stochastic microstructures gradually grow with increasing $L O$ at high levels of $F$. (b) The periodicity and height of structures decreases with increasing LO. High LO leads to a clear homogenous nanoscale roughness.

When discussing the creation of the surface structure depending on the different $L O$ and $P O$ parameters, the dynamics of the laser structuring process itself has to be considered. Firstly, when looking at a single femtosecond laser pulse, heat conduction occurs if the boiling temperature is not exceeded [40]. Initial absorption of the laser irradiation of a laser pulse occurs from the free electrons in the first femtoseconds due to inverse bremsstrahlung. Subsequently, fast energy relaxation in the electron subsystem, energy transfer to the lattice (induced by electron-phonon coupling) and thermal diffusion in the material occurs [38,41]. If the material temperature crosses the boiling point of the material, evaporation or rather sublimation of material takes place as a direct solid-vapor/plasma transition [20]. This effect is caused by inhibited or restricted energy transverse of heated electrons to the lattice and rapid electron cooling at a time scale of around 1-3 ps [42-44]. Energy from the electron gas cannot be migrated into the ion lattice and leads to a temperature gap between electron and lattice [45]. Hot excited electrons are in a thermal non-equilibrium with high pressure in the first picoseconds [46]. Ultra-high heating rates lead to a transition to an overcritical fluid with a temperature close to the critical thermodynamic temperature [47] and thermionic and photoelectric effects lead to an emission of electrons [48]. This high-pressure mixture expands rapidly and leads to phase explosion [45]. A plasma plume is consequently formed afterwards with constituents of electrons in tens of picoseconds. Atomic, or rather ionic, mass is ejected up to nanoseconds and greater particles $(\mathrm{nm})$ are cast out in a microsecond time scale [49]. 


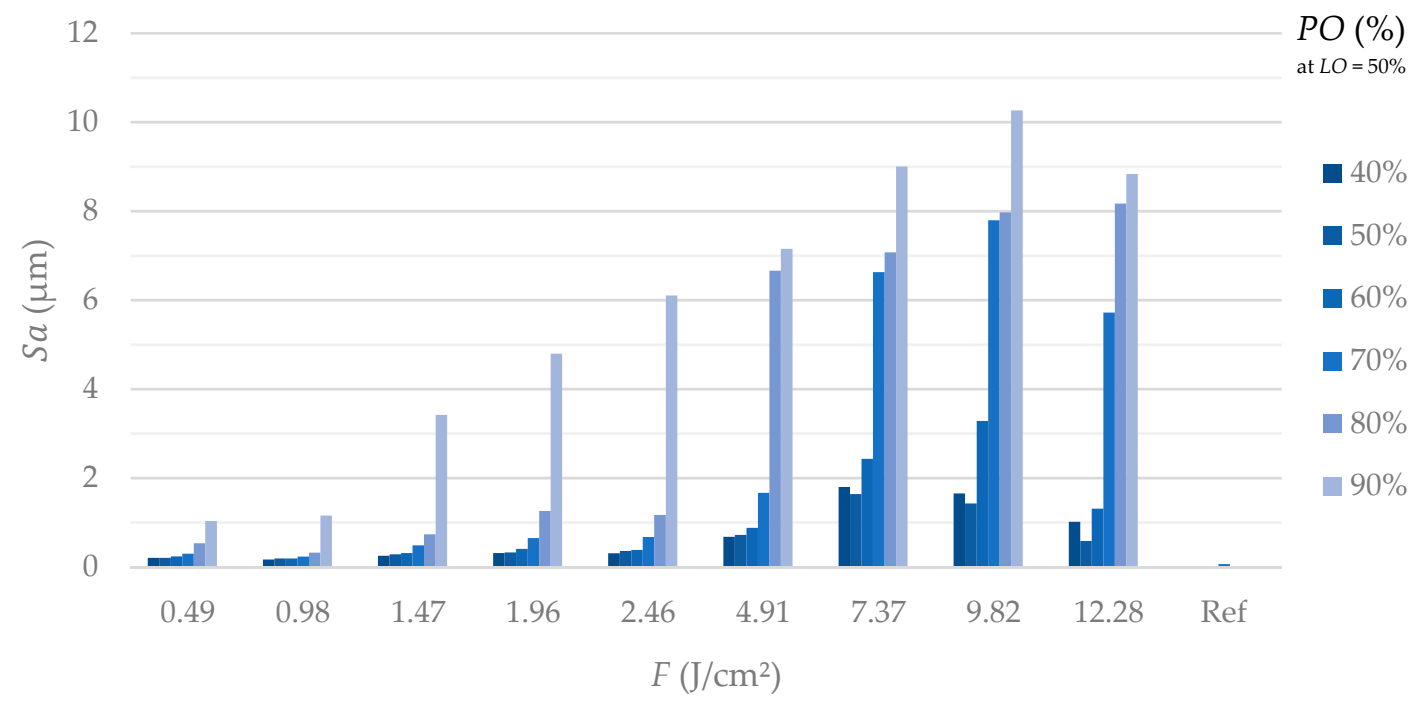

(a)

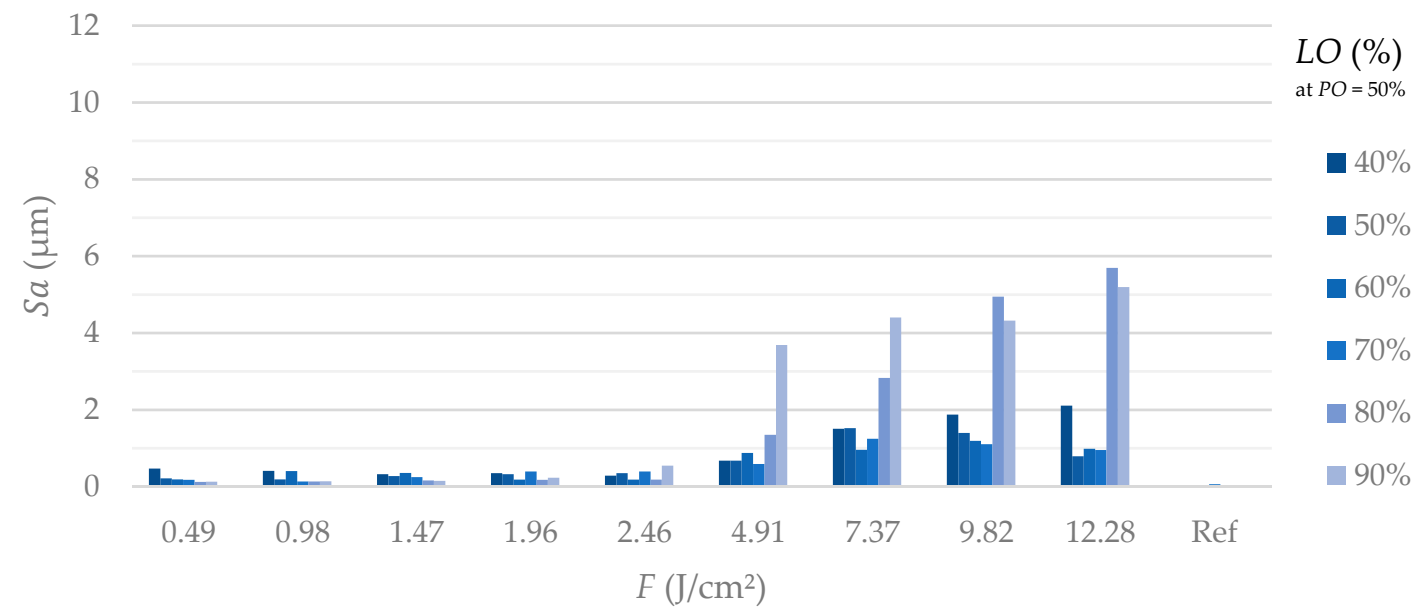

(b)

Figure 7. Average area surface roughness ( $S a$ ) after laser processing related to the reference (Ref). (a) A clear increase of the roughness can be obtained with increasing $P O$ at all fluences. (b) A higher scanning line overlap leads also to an increase in roughness above a fluence of approx. $4.91 \mathrm{~J} / \mathrm{cm}^{2}$. Firstly, a higher $L O$ leads to a decreased roughness at low fluences. Generally, the determined average area surface roughness is less compared to that obtained at corresponding levels of $P O$ (and the same energy input). At fluences from $7.37 \mathrm{~J} / \mathrm{cm}^{2}$ to $12.28 \mathrm{~J} / \mathrm{cm}^{2}$, a minor increase in roughness can be detected at a low level of $L O$ due to a clear trench formation.

When considering multiple laser shots at high repetition rates, several effects occur. If the ablated material results in a plasma plume, interaction with the incoming laser light by the next laser pulse takes place and leads to an inefficiency of energy deposition in the laser spot, which is referred to as plasma shielding [40,49]. Photoionization of excited atoms and electron-ion as well as electron-neutral bremsstrahlung are the mechanisms that lead to an absorption of a part of the incident photons before hitting the target and, consequently, to an increase of the plasma temperature [32]. The absorption coefficient of the plasma is proportional to the amount of vaporized material [50,51]. Conglomerated material after laser ablation in air represent a further source for absorption of the incident light and is expected at a repetition rate of hundreds of $\mathrm{kHz}$ [41]. This study was conducted with a repetition rate of $226.8 \mathrm{kHz}$. Consequently, plasma shielding must be considered, especially at a high PO. However, even though the applied repetition rate was the same for $P O$ and $L O$, plasma shielding cannot be the 
driving force for different surface characteristics since it would instead lead to a decrease in ablation at increasing levels of $P O$ or $L O$.

Ablation threshold reduction by a sequence of laser pulses with low repetition rates is explained by chemical changes and crystallographic material modifications and shown on titanium nitride films [52], where heat dissipation has taken place and the initial surface temperature is given. Consequently, even a single laser pulse below the gentle threshold can lead to structural or chemical modifications [30]. For multiple laser pulse irradiation with low repetition rates, it was reported that previous pulses result in an accumulation of defects, specified as long-lived bulk defects, like Frenkel defects. The accumulation is related to a storage cycle of thermal stress-strain energy due to the number of pulses and explained by the incubation model [46]. Due to the accumulation of defects, phase explosion can be evoked at lower fluences after a sufficient number of incubation pulses at low repetition rates [36]. A reduction in the ablation threshold with an increasing number of laser pulses at stationary irradiation and a repetition rate of $100 \mathrm{~Hz}$ was shown on different metals and explained by the incubation effect [23]. Physical mechanisms of the incubation effect have not yet been fully elucidated. A strengthened incubation effect was observed for a repetition rate of over $600 \mathrm{kHz}$ and can be explained by heat accumulation [53]. In this study, the repetition rate and number of over scans were maintained at a constant of $226.8 \mathrm{kHz}$ and a number of 50, respectively, for all $P O$ and $L O$ parameters. Thus, the incubation effect due to structural changes must be taken into consideration, but the time sequence of the pulses and scanning strategy probably has the dominant role.

If a high repetition rate is used, yielded energy cannot dissipate. The following laser pulses lead to heat accumulation and heating of the illuminated area takes place. It is obvious, by considering Figures 3 and 4, that the formation of microstructures and higher amount of ablation is achieved at lower levels of $P O$ compared to $L O$ at a constant energy input. This effect is confirmed by the height elevation profiles at high fluences, as depicted in Figures 5a and 6a. Height profiles show, that microstructures are formed at higher levels of $L O$ in comparison to corresponding levels of $P O$. Furthermore, a higher $P O$ ablates more material even at lower fluences which ultimately results in higher roughnesses, as can be seen in Figure 7. The duration for the structuring of one line $(7 \mathrm{~mm})$ in this study is in the range of several milliseconds ( $v_{S}$ from 0.82 to $4.9 \mathrm{~m} / \mathrm{s}$ ). The time interval between two consecutive laser pulses is several microseconds due to the repetition rate of $226.8 \mathrm{kHz}$. Thus, a higher $P O$ seems to lead to a stronger accumulation effect than is the case at corresponding levels of $L O$ due to a shorter time sequence in laser pulse irradiation. Heat dissipation through thermal conduction is insufficient and the temperature of the material in the irradiated spot gradually increases due to consecutive laser pulses applied on the same area. Consequently, pronounced phase explosion is evoked due to a higher $P O$ and a formation of microstructures occurs at lower $P O$ values compared to the corresponding $L O$ values. Higher repetition rates usually result in lower pulse energies, which makes this conclusion interesting for multiple-beam laser treatment. By means of a nanosecond laser, an increase of crater depth was caused by the heat accumulation effect at repetition rates around 100-1000 $\mathrm{Hz}$ [54]. Consecutive laser pulses lead to a continuous heating of the illuminated area even at kilohertz repetition rates [30]. Consequently, the ablation process takes place at different surface temperatures. In an extreme case at a repetition rate of $133 \mathrm{MHz}$, quasi-CW heating effects have been shown on aluminum foils with a burst of mode-locked picosecond laser $[50,55]$. Therefore, with a repetition rate of $226.8 \mathrm{kHz}$ applied in this study, it can be concluded that the aforementioned phenomena for high repetition rates are responsible for presented different surface characteristics achieved at corresponding levels of $P O$ and $L O$. At high $P O s$, microstructures can be formed at lower fluences and a higher roughness modification is evoked compared to laser structuring at corresponding LOs. Numerical models have shown the effect of heat accumulation on surface temperature in multi-pulse laser processing [56,57]. Adsorbed energy that is not used for rapid evaporation or sublimation of the material remains in the surface and can lead to heat accumulation in laser processes with a high repetition rate. Consequently, ablation by the next pulse starts at an increased surface temperature and affects the ablation threshold, which is consistent with the findings of this study. 
In summary, scanning strategies should aim at high pulse overlap if fast modification of the surface, a maximized volume of ablated material and a high roughness increase is desired. An appropriate or relatively higher scanning line overlap leads to a homogenous distribution of nanostructures and helps avoid strong waviness of the laser treated surface. Several studies have already shown that laser induced periodic surface structures (FLIPSS, LIPSS) provide favorable conditions for cell attachment $[15,17,58,59]$. The impact of two selected micro and two selected FLIPSS structures presented in the current study on the cell adhesion of MG-63 cells have already been investigated [15]. It could be demonstrated, that the osteoblasts adhered tightly, especially to the two investigated FLIPSS-structured surfaces, and it was found that the spreading was superior on these surfaces. The findings of this cell study can be used in conjunction with the current study for tailoring of Ti6Al4V implant surfaces with improved cell behavior

It is reported in the literature, fs laser treatment affects the crystallographic, chemical, and mechanical properties of the sublayer on the surface in a range of several hundreds of nanometers [60-62] and, consequently, the implant performance. Therefore, further research should focus on the effect of laser treatment parameters on the dimension and properties of the heat affected zone (HAZ) and internal structure in the nano- and microstructures on Ti6Al4V, such as layer thickness, grain size and growth within the layer, and derived mechanical properties. Furthermore, to enhance the mechanical properties of the surface such as the tribological behavior or nanohardness, additional coating and sputtering processes [63-65] or chemical modifications of the titanium alloy or surface could be beneficial [66-68].

\section{Conclusions}

The effects of laser pulse overlap $(P O)$ and scanning line overlap $(L O)$, as well as applied fluence on the surface topography of Ti6Al4V, have been investigated in detail. Four different surface patterns could be identified depending on the applied laser parameters and scanning strategy. Micrometric ripples (MR) and femtosecond laser-induced periodic surface structures (FLIPSS) could be distinguished. Furthermore, the formation of micro-craters and pillared microstructures have also been observed. The microstructure is partially superimposed by the nanostructure, leading to a double scale formation. The average area surface roughness has been determined to quantify the ablation amount in order to specify the ablation regime. In particular, it has been found that the effects of $P O$ and $L O$ on the strong ablation regime are essentially different.

The results can be summarized as follows:

- It has been demonstrated that the strong ablation threshold depends on $P O$ and $L O$ as well as on the fluence.

- High POs cause extended phase explosion and heat accumulation which ultimately leads to a decrease of the strong ablation threshold.

- Higher POs should be preferred if high efficiency regarding the ablation amount and roughness is desired.

- A higher $L O$ leads to a homogenous formation of nanostructures at low fluences with less waviness.

The influence of the pulse duration and the laser wavelength on the formation of nano and microstructures should be quantified in further studies to enhance laser processing strategies on Ti6Al4V, particularly with regard to high repetition laser processes and ultrafast laser systems. Lastly, the laser parameter findings presented in this study can be used for tailoring of proper structural designs of biomedical implants in order to adjust the cell material interaction of medical implants for dental and orthopedic applications. Further studies should also focus on the adhesion and proliferation of cells seeded onto laser-structured surfaces with regard to specific applications.

Author Contributions: Conceptualization: G.S., U.D. and H.S.; data curation: G.S.; formal analysis: G.S.; funding acquisition: H.S.; investigation: G.S. and U.D.; methodology: G.S.; supervision: H.S.; validation: G.S.; 
visualization: G.S. and U.D.; writing-original draft: G.S.; writing—review and editing: G.S. and H.S. All authors have read and agreed to the published version of the manuscript.

Funding: This research was funded by the Federal Ministry of Education and Research (funding code: 03WKCU6B; Innovative Regional Growth Cores "MikroLas" which is part of the initiative "Entrepreneurial Regions"- "The BMBF Innovation Initiative for the New German Länder"). This work was supported by the German Research Foundation (DFG, grant number INST 264/124-1 FUGG). We also acknowledge financial support by the DFG and the University Rostock within the funding program Open Access Publishing.

Acknowledgments: The authors thank D. Hohlfeld and F. Lange ("Micro- and Nanotechnology of Electronic Systems", Rostock) for SEM-Imaging.

Conflicts of Interest: The authors declare no conflict of interest. The funders had no role in the design of the study; in the collection, analyses, or interpretation of data; in the writing of the manuscript; or in the decision to publish the results.

\section{References}

1. Brunette, D.M.; Tengvall, P.; Textor, M.; Thomsen, P. Titanium in Medicine. Material Science, Surface Science, Engineering, Biological Responses and Medical Applications; Springer: Berlin/Heidelberg, Germany, 2001; ISBN 9783642631191.

2. Flemming, R.G.; Murphy, C.J.; Abrams, G.A.; Goodman, S.L.; Nealey, P.F. Effects of synthetic micro- and nano-structured surfaces on cell behavior. Biomaterials 1999, 20, 573-588. [CrossRef]

3. Sykaras, N.; Iacopino, A.M.; Marker, V.A.; Triplett, R.G.; Woody, R.D. Implant materials, designs, and surface topographies: Their effect on osseointegration. A literature review. Int. J. Oral Maxillofac. Implant. 2000, 15, 675-690.

4. Nuutinen, T.; Silvennoinen, M.; Päiväsaari, K.; Vahimaa, P. Control of cultured human cells with femtosecond laser ablated patterns on steel and plastic surfaces. Biomed. Microdevices 2013, 15, 279-288. [CrossRef] [PubMed]

5. Wang, C.; Hu, H.; Li, Z.; Shen, Y.; Xu, Y.; Zhang, G.; Zeng, X.; Deng, J.; Zhao, S.; Ren, T.; et al. Enhanced Osseointegration of Titanium Alloy Implants with Laser Microgrooved Surfaces and Graphene Oxide Coating. ACS Appl. Mater. Interfaces 2019, 11, 39470-39483. [CrossRef]

6. Staehlke, S.; Koertge, A.; Nebe, B. Intracellular calcium dynamics dependent on defined microtopographical features of titanium. Biomaterials 2015, 46, 48-57. [CrossRef]

7. Bowers, K.T.; Keller, J.C.; Randolph, B.A.; Wick, D.G.; Michaels, C.M. Optimization of surface micromorphology for enhanced osteoblast responses in vitro. Int. J. Oral Maxillofac. Implant. 1992, 7, 302-310.

8. Wennerberg, A. Experimental study of turned and grit-blasted screw-shaped implants with special emphasis on effects of blasting material and surface topography. Biomaterials 1996, 17, 15-22. [CrossRef]

9. Taborelli, M.; Jobin, M.; François, P.; Vaudaux, P.; Tonetti, M.; Szmukler-Moncler, S.; Simpson, J.P.; Descouts, P. Influence of surface treatments developed for oral implants on the physical and biological properties of titanium. (I) Surface characterization. Clin. Oral Implant. Res. 1997, 8, 208-216. [CrossRef]

10. Cordioli, G.; Majzoub, Z.; Piattelli, A.; Scarano, A. Removal torque and histomorphometric investigation of 4 different titanium surfaces: An experimental study in the rabbit tibia. Int. J. Oral Maxillofac. Implant. 2000, $15,668-674$.

11. Zinger, O.; Zhao, G.; Schwartz, Z.; Simpson, J.; Wieland, M.; Landolt, D.; Boyan, B. Differential regulation of osteoblasts by substrate microstructural features. Biomaterials 2005, 26, 1837-1847. [CrossRef]

12. Gaggl, A.; Schultes, G.; Müller, W.D.; Kärcher, H. Scanning electron microscopical analysis of laser-treated titanium implant surfaces-A comparative study. Biomaterials 2000, 21, 1067-1073. [CrossRef]

13. Schnell, G.; Jagow, C.; Springer, A.; Frank, M.; Seitz, H. Time-Dependent Anisotropic Wetting Behavior of Deterministic Structures of Different Strut Widths on Ti6Al4V. Metals 2019, 9, 938. [CrossRef]

14. Cunha, A.; Serro, A.P.; Oliveira, V.; Almeida, A.; Vilar, R.; Durrieu, M.-C. Wetting behaviour of femtosecond laser textured Ti-6Al-4V surfaces. Appl. Surf. Sci. 2013, 265, 688-696. [CrossRef]

15. Schnell, G.; Staehlke, S.; Duenow, U.; Nebe, J.B.; Seitz, H. Femtosecond Laser Nano/Micro Textured Ti6Al4V Surfaces-Effect on Wetting and MG-63 Cell Adhesion. Materials 2019, 12, 2210. [CrossRef] 
16. Shinonaga, T.; Kinoshita, S.; Okamoto, Y.; Tsukamoto, M.; Okada, A. Formation of Periodic Nanostructures with Femtosecond Laser for Creation of New Functional Biomaterials. Procedia CIRP 2016, 42, 57-61. [CrossRef]

17. Gnilitskyi, I.; Pogorielov, M.; Viter, R.; Ferraria, A.M.; Carapeto, A.P.; Oleshko, O.; Orazi, L.; Mishchenko, O. Cell and tissue response to nanotextured Ti6Al4V and $\mathrm{Zr}$ implants using high-speed femtosecond laser-induced periodic surface structures. Nanomedicine 2019, 21, 102036. [CrossRef] [PubMed]

18. Dumas, V.; Guignandon, A.; Vico, L.; Mauclair, C.; Zapata, X.; Linossier, M.T.; Bouleftour, W.; Granier, J.; Peyroche, S.; Dumas, J.-C.; et al. Femtosecond laser nano/micro patterning of titanium influences mesenchymal stem cell adhesion and commitment. Biomed. Mater. 2015, 10, 55002. [CrossRef] [PubMed]

19. Vorobyev, A.Y.; Guo, C. Femtosecond laser structuring of titanium implants. Appl. Surf. Sci. 2007, 253, 7272-7280. [CrossRef]

20. Chichkov, B.N.; Momma, C.; Nolte, S.; Alvensleben, F.; Tünnermann, A. Femtosecond, picosecond and nanosecond laser ablation of solids. Appl. Phys. A 1996, 63, 109-115. [CrossRef]

21. Le Harzic, R.; Huot, N.; Audouard, E.; Jonin, C.; Laporte, P.; Valette, S.; Fraczkiewicz, A.; Fortunier, R. Comparison of heat-affected zones due to nanosecond and femtosecond laser pulses using transmission electronic microscopy. Appl. Phys. Lett. 2002, 80, 3886-3888. [CrossRef]

22. Tsukamoto, M.; Asuka, K.; Nakano, H.; Hashida, M.; Katto, M.; Abe, N.; Fujita, M. Periodic microstructures produced by femtosecond laser irradiation on titanium plate. Vacuum 2006, 80, 1346-1350. [CrossRef]

23. Bizi-Bandoki, P.; Benayoun, S.; Valette, S.; Beaugiraud, B.; Audouard, E. Modifications of roughness and wettability properties of metals induced by femtosecond laser treatment. Appl. Surf. Sci. 2011, 257, 5213-5218. [CrossRef]

24. Nayak, B.K.; Gupta, M.C.; Kolasinski, K.W. Formation of nano-textured conical microstructures in titanium metal surface by femtosecond laser irradiation. Appl. Phys. A 2008, 90, 399-402. [CrossRef]

25. Gnilitskyi, I.; Derrien, T.J.-Y.; Levy, Y.; Bulgakova, N.M.; Mocek, T.; Orazi, L. High-speed manufacturing of highly regular femtosecond laser-induced periodic surface structures: Physical origin of regularity. Sci. Rep. 2017, 7, 8485. [CrossRef]

26. Ionin, A.A.; Kudryashov, S.I.; Makarov, S.V.; Rudenko, A.A.; Seleznev, L.V.; Sinitsyn, D.V.; Golosov, E.V.; Kolobov, Y.R.; Ligachev, A.E. Beam spatial profile effect on femtosecond laser surface structuring of titanium in scanning regime. Appl. Surf. Sci. 2013, 284, 634-637. [CrossRef]

27. Oliveira, V.; Ausset, S.; Vilar, R. Surface micro/nanostructuring of titanium under stationary and non-stationary femtosecond laser irradiation. Appl. Surf. Sci. 2009, 255, 7556-7560. [CrossRef]

28. Hashida, M.; Semerok, A.F.; Gobert, O.; Petite, G.; Izawa, Y.; Wagner, J.F. Ablation threshold dependence on pulse duration for copper. Appl. Surf. Sci. 2002, 197-198, 862-867. [CrossRef]

29. Trtica, M.S.; Radak, B.B.; Gakovic, B.M.; Milovanovic, D.S.; Batani, D.; Desai, T. Surface modifications of Ti6Al4V by a picosecond Nd:YAG laser. Laser Part. Beams 2009, 27, 85-90. [CrossRef]

30. Raciukaitis, G.; Brikas, M.; Gecys, P.; Gedvilas, M. Accumulation Effects in Laser Ablation of Metals with High-Repetition-Rate Lasers. In Proceedings of the High-Power Laser Ablation VII, High-Power Laser Ablation 2008, Taos, NM, USA, 20 April 2008.

31. Mannion, P.T.; Magee, J.; Coyne, E.; O'Connor, G.M.; Glynn, T.J. The effect of damage accumulation behaviour on ablation thresholds and damage morphology in ultrafast laser micro-machining of common metals in air. Appl. Surf. Sci. 2004, 233, 275-287. [CrossRef]

32. Cristoforetti, G.; Legnaioli, S.; Palleschi, V.; Tognoni, E.; Benedetti, P.A. Observation of different mass removal regimes during the laser ablation of an aluminium target in air. J. Anal. Spectrom. 2008, 23, 1518. [CrossRef]

33. Vorobyev, A.Y.; Guo, C. Direct femtosecond laser surface nano/microstructuring and its applications. Laser Photonics Rev. 2013, 7, 385-407. [CrossRef]

34. Bonse, J.; Hohm, S.; Kirner, S.V.; Rosenfeld, A.; Kruger, J. Laser-Induced Periodic Surface Structures-A Scientific Evergreen. IEEE J. Sel. Top. Quantum Electron. 2017, 23, 1. [CrossRef]

35. Wu, B.; Zhou, M.; Li, J.; Ye, X.; Li, G.; Cai, L. Superhydrophobic surfaces fabricated by microstructuring of stainless steel using a femtosecond laser. Appl. Surf. Sci. 2009, 256, 61-66. [CrossRef]

36. Ashkenasi, D.; Rosenfeld, A.; Varel, H.; Wahmer, M.; Campbell, E.E.B. Laser processing of sapphire with picosecond and sub-picosecond pulses. Appl. Surf. Sci. 1997, 120, 65-80. [CrossRef] 
37. Wang, W.; Mei, X.; Jiang, G.; Lei, S.; Yang, C. Effect of two typical focus positions on microstructure shape and morphology in femtosecond laser multi-pulse ablation of metals. Appl. Surf. Sci. 2008, 255, 2303-2311. [CrossRef]

38. Nolte, S.; Momma, C.; Jacobs, H.; Tünnermann, A.; Chichkov, B.N.; Wellegehausen, B.; Welling, H. Ablation of metals by ultrashort laser pulses. J. Opt. Soc. Am. B 1997, 14, 2716. [CrossRef]

39. Bulgakova, N.M.; Bulgakov, A.V. Pulsed laser ablation of solids: Transition from normal vaporization to phase explosion. Appl. Phys. A 2001, 73, 199-208. [CrossRef]

40. Tan, S.; Wu, J.; Zhang, Y.; Wang, M.; Ou, Y. A Model of Ultra-Short Pulsed Laser Ablation of Metal with Considering Plasma Shielding and Non-Fourier Effect. Energies 2018, 11, 3163. [CrossRef]

41. König, J.; Nolte, S.; Tünnermann, A. Plasma evolution during metal ablation with ultrashort laser pulses. Opt. Express 2005, 13, 10597-10607. [CrossRef] [PubMed]

42. Wang, X.Y.; Riffe, D.M.; Lee, Y.-S.; Downer, M.C. Time-resolved electron-temperature measurement in a highly excited gold target using femtosecond thermionic emission. Phys. Rev. B Condens. Matter 1994, 50, 8016-8019. [CrossRef]

43. Fann, W.S.; Storz, R.; Tom, H.W.K.; Bokor, J. Electron thermalization in gold. Phys. Rev. B Condens. Matter 1992, 46, 13592-13595. [CrossRef] [PubMed]

44. Schoenlein, R.W.; Lin, W.Z.; Fujimoto, J.G.; Eesley, G.L. Femtosecond studies of nonequilibrium electronic processes in metals. Phys. Rev. Lett. 1987, 58, 1680-1683. [CrossRef] [PubMed]

45. Leitz, K.-H.; Redlingshöfer, B.; Reg, Y.; Otto, A.; Schmidt, M. Metal Ablation with Short and Ultrashort Laser Pulses. Phys. Procedia 2011, 12, 230-238. [CrossRef]

46. Güdde, J.; Hohlfeld, J.; Müller, J.; Matthias, E. Damage threshold dependence on electron-phonon coupling in Au and Ni films. Appl. Surf. Sci. 1998, 127, 40-45. [CrossRef]

47. Rethfeld, B.; Sokolowski-Tinten, K.; Temnov, V.V.; Kudryashov, S.I.; Bialkowski, J.; Cavalleri, A.; von der Linde, D. Ablation Dynamics of Solids Heated by Femtosecond Laser Pulses. In Proceedings of the Nonresonant Laser-Matter Interaction (NLMI-10), St. Petersburg, Russia, 21 August 2000; pp. 186-196.

48. Korte, F.; Serbin, J.; Koch, J.; Egbert, A.; Fallnich, C.; Ostendorf, A.; Chichkov, B. Towards nanostructuring with femtosecond. Appl. Phys. A 2003, 77, 229-235. [CrossRef]

49. Russo, R.E.; Mao, X.L.; Liu, H.C.; Yoo, J.H.; Mao, S.S. Time-resolved plasma diagnostics and mass removal during single-pulse laser ablation. Appl. Phys. A 1999, 69, S887-S894. [CrossRef]

50. Stauter, C.; Fontaine, J.; Engel, T. Real-time determination of the amount of removed material during short pulses laser micromachining. Appl. Surf. Sci. 1996, 96-98, 522-527. [CrossRef]

51. Aguilera, J.A.; Aragón, C.; Peñalba, F. Plasma shielding effect in laser ablation of metallic samples and its influence on LIBS analysis. Appl. Surf. Sci. 1998, 127-129, 309-314. [CrossRef]

52. Bonse, J.; Sturm, H.; Schmidt, D.; Kautek, W. Chemical, morphological and accumulation phenomena in ultrashort-pulse laser ablation of TiN in air. Appl. Phys. A 2000, 71, 657-665. [CrossRef]

53. Di Niso, F.; Gaudiuso, C.; Sibillano, T.; Mezzapesa, F.P.; Ancona, A.; Lugarà, P.M. Influence of the Repetition Rate and Pulse Duration on the Incubation Effect in Multiple-Shots Ultrafast Laser Ablation of Steel. Phys. Procedia 2013, 41, 698-707. [CrossRef]

54. Brygo, F.; Dutouquet, C.; Le Guern, F.; Oltra, R.; Semerok, A.; Weulersse, J.M. Laser fluence, repetition rate and pulse duration effects on paint ablation. Appl. Surf. Sci. 2006, 252, 2131-2138. [CrossRef]

55. Lapczyna, M.; Chen, K.P.; Herman, P.R.; Tan, H.W.; Marjoribanks, R.S. Ultra high repetition rate (133 MHz) laser ablation of aluminum with 1.2-ps pulses. Appl. Phys. A 1999, 69, S883-S886. [CrossRef]

56. Weber, R.; Graf, T.; Berger, P.; Onuseit, V.; Wiedenmann, M.; Freitag, C.; Feuer, A. Heat accumulation during pulsed laser materials processing. Opt. Express 2014, 22, 11312-11324. [CrossRef] [PubMed]

57. Bauer, F.; Michalowski, A.; Kiedrowski, T.; Nolte, S. Heat accumulation in ultra-short pulsed scanning laser ablation of metals. Opt. Express 2015, 23, 1035-1043. [CrossRef]

58. Bonse, J.; Kirner, S.V.; Höhm, S.; Epperlein, N.; Spaltmann, D.; Rosenfeld, A.; Krüger, J. Applications of Laser-Induced Periodic Surface Structures (LIPSS). In Proceedings of the Laser-based Micro- and Nanoprocessing XI, SPIE LASE, San Francisco, CA, USA, 28 January 2017.

59. Raimbault, O.; Benayoun, S.; Anselme, K.; Mauclair, C.; Bourgade, T.; Kietzig, A.-M.; Girard-Lauriault, P.-L.; Valette, S.; Donnet, C. The effects of femtosecond laser-textured Ti-6Al-4V on wettability and cell response. Mater. Sci. Eng. C Mater. Biol. Appl. 2016, 69, 311-320. [CrossRef] 
60. Thompson, H.; Lammatao, J.; Hecht, M.D.; Yousif, A.; Campbell, B.R.; Picard, Y.N. Ultrashort Pulsed Laser Induced Heat Affected Zones Characterized by Ion Channeling Contrast Imaging. Microsc. Microanal. 2014, 20, 1480-1481. [CrossRef]

61. Kolobov, Y.R.; Golosov, E.V.; Vershinina, T.N.; Zhidkov, M.V.; Ionin, A.A.; Kudryashov, S.I.; Makarov, S.V.; Seleznev, L.V.; Sinitsyn, D.V.; Ligachev, A.E. Structural transformation and residual stresses in surface layers of $\alpha+\beta$ titanium alloys nanotextured by femtosecond laser pulses. Appl. Phys. A 2015, 119, 241-247. [CrossRef]

62. Bonse, J.; Krüger, J. Probing the heat affected zone by chemical modifications in femtosecond pulse laser ablation of titanium nitride films in air. Appl. Phys. Lett. 2010, 107, 54902. [CrossRef]

63. Amanov, A.; Sasaki, S. A study on the tribological characteristics of duplex-treated Ti-6Al-4V alloy under oil-lubricated sliding conditions. Tribol. Int. 2013, 64, 155-163. [CrossRef]

64. Bonse, J.; Kirner, S.V.; Koter, R.; Pentzien, S.; Spaltmann, D.; Krüger, J. Femtosecond laser-induced periodic surface structures on titanium nitride coatings for tribological applications. Appl. Surf. Sci. 2017, 418, 572-579. [CrossRef]

65. Kim, Y.S.; Park, H.J.; Mun, S.C.; Jumaev, E.; Hong, S.H.; Song, G.; Kim, J.T.; Park, Y.K.; Kim, K.S.; Jeong, S.I.; et al. Investigation of structure and mechanical properties of TiZrHfNiCuCo high entropy alloy thin films synthesized by magnetron sputtering. J. Alloy. Compd. 2019, 797, 834-841. [CrossRef]

66. Long, M.; Rack, H. Titanium alloys in total joint replacement-A materials science perspective. Biomaterials 1998, 19, 1621-1639. [CrossRef]

67. Hwang, Y.J.; Hong, S.H.; Kim, Y.S.; Park, H.J.; Jeong, Y.B.; Kim, J.T.; Kim, K.B. Influence of silicon content on microstructure and mechanical properties of Ti-Cr-Si alloys. J. Alloy. Compd. 2018, 737, 53-57. [CrossRef]

68. Liu, X.; Chu, P.; Ding, C. Surface modification of titanium, titanium alloys, and related materials for biomedical applications. Mater. Sci. Eng. R Rep. 2004, 47, 49-121. [CrossRef]

(C) 2020 by the authors. Licensee MDPI, Basel, Switzerland. This article is an open access article distributed under the terms and conditions of the Creative Commons Attribution (CC BY) license (http://creativecommons.org/licenses/by/4.0/). 